Nat Rev Gastroenterol Hepatol. 2013 August ; 10(8): 487-494. doi:10.1038/nrgastro.2013.86.

\title{
Genetics and alcoholism
}

\author{
Howard J. Edenberg ${ }^{\star}, \dagger$ and Tatiana Foroud ${ }^{\dagger}$ \\ *Department of Biochemistry and Molecular Biology, Indiana University School of Medicine, \\ Indianapolis, IN 46202 \\ tDepartment of Medical and Molecular Genetics, Indiana University School of Medicine, \\ Indianapolis, IN 46202
}

\begin{abstract}
Alcohol is widely consumed, but excessive use creates serious physical, psychological and social problems and contributes to many diseases. Alcoholism (alcohol dependence, alcohol use disorders) is a maladaptive pattern of excessive drinking leading to serious problems. Abundant evidence indicates that alcoholism is a complex genetic disease, with variations in a large number of genes affecting risk. Some of these genes have been identified, including two genes of alcohol metabolism, $A D H 1 B$ and $A L D H 2$, that have the strongest known affects on risk for alcoholism. Studies are revealing other genes in which variants impact risk for alcoholism or related traits, including GABRA2, CHRM2, KCNJ6, and AUTS2. As larger samples are assembled and more variants analyzed, a much fuller picture of the many genes and pathways that impact risk will be discovered.
\end{abstract}

\section{Introduction}

Alcohol (ethanol) is consumed by many throughout the world. Consumed in low amounts (up to 1 drink per day for women who are not pregnant, 2 drinks per day for men) it can have some beneficial effects on cardiovascular health. But the excessive use of alcohol creates many serious problems: physical, psychological and social. In addition to alcohol use disorders, many other diseases are affected by alcohol exposure, including alcoholic cirrhosis, alcoholic pancreatitis, cancers of the upper GI tract and the liver, cardiovascular diseases, breast cancer, diabetes and fetal alcohol syndrome ${ }^{1}$. Men tend to drink more heavily and more frequently than women, putting them at higher risk of disease and death. The World Health Organization Global Status Report on Alcohol and Health ${ }^{2}$ and The Global Burden of Disease Study $2010^{3}$ both list alcohol as the third leading risk factor for deaths and disabilities. WHO estimates that it causes approximately 2.5 million deaths per year, almost $4 \%$ of total deaths worldwide and $6.2 \%$ of all male deaths ${ }^{2}$.

Alcohol abuse and alcohol dependence are maladaptive patterns of drinking that cause repeated, serious problems for the drinker. Alcohol dependence is currently defined in the Diagnostic and Statistical Manual of Mental Disorders ${ }^{4}$ (DSM-IV-TR, henceforth DSM-IV)

Correspondence: Howard J. Edenberg, Ph.D., Department of Biochemistry and Molecular Biology, Indiana University School of Medicine, 635 Barnhill Drive, MS4063, Indianapolis, IN 46202-5122, edenberg@iu.edu. 
as meeting at least 3 of 7 criteria (Table 1). Alcohol abuse is defined by meeting two of four criteria but not meeting criteria for dependence; abuse criteria are often met on the path to dependence. Based on data from the 2001-2002 National Epidemiological Survey on Alcohol and Related Conditions (NESARC), a large general population sample from the US, in any one year 3.8\% of Americans meet DSM-IV criteria for alcohol dependence and an additional 4.7\% meet DSM-IV criteria for abuse ${ }^{5}$. A follow-up study in 2004-2005 showed 4.4\% of Americans met these criteria for alcohol dependence and an additional 5.3\% met criteria for alcohol abuse ${ }^{6,7}$. When considering lifetime risk for alcohol use disorders, the rates are higher: $12.5 \%$ of individuals meet criteria for alcohol dependence at some stage during their life, and another $17.8 \%$ meet criteria for alcohol abuse ${ }^{5}$.

Diagnostic criteria are being modified. Instead of separate categories for abuse and dependence, DSM- $5^{8}$ now defines alcohol use disorder (AUD), which requires an individual to meet at least 2 of 11 criteria, 10 from DSM-IV with the addition of craving (Table 1). DSM-5 differentiates moderate AUD ( 2 or 3 criteria) from severe AUD (4 or more criteria). Based upon the 2004-2005 dataset of the National Epidemiologic Survey on Alcohol and Related Conditions (NESARC), 80.5\% of the individuals who met criteria for DSM-IV alcohol dependence also met criteria for DSM-5 severe AUD ${ }^{6,7}$. Overall, in the NESARC 2004-2005 dataset 10.8\% of the individuals met a diagnosis of AUD during the preceding year ${ }^{6,7}$. In an Australian population sample, the prevalence of a DSM-5 AUD was 9.7\% 9 .

\section{The genetics of alcohol dependence}

Alcohol dependence (alcoholism), the most severe alcohol use disorder, is a complex genetic disease. Alcoholism has long been noted to run in families, but that alone is not sufficient to demonstrate that genetic factors contribute to risk. Many independent lines of evidence point to genetic contributions to its etiology. Adoption studies show that alcoholism in adoptees correlates more strongly with their biological parents than their adoptive parents ${ }^{10-13}$. Twin studies in the US and Europe suggest that approximately $45-65 \%$ of the liability is due to genetic factors ${ }^{14-17}$. Animal studies also demonstrate genetic liability; mice and rats have been selectively bred for many traits associated with alcohol dependence, including alcohol preference, alcohol sensitivity, and withdrawal sensitivity ${ }^{18,19}$. The ability to genetically select for these traits demonstrates that there are genetic bases for them, and that different genes contribute to different aspects of the phenotype. Taken together, there is overwhelming evidence that genetic variations contribute to the risk for alcohol dependence.

It should be emphasized that while genetic differences affect risk, there is no "gene for alcoholism," and both environmental and social factors weigh heavily on the outcome. Genetic factors affect the risk not only for alcohol dependence, but also the level of alcohol consumption and the risk for alcohol-associated diseases, including cirrhosis and upper GI cancers. Knowing that genetic factors affect risk does not mean that we know which specific variants contribute, nor how. This is an area of active research as new genes and variants are being identified. 
It is likely that, as for most complex diseases, alcohol dependence and AUDs are due to variations in hundreds of genes, interacting with different social environments. An additional challenge in the search for genetic variants that affect the risk for AUDs is that there is extensive clinical heterogeneity among those meeting criteria. Because the diagnosis of an AUD requires the presence of a set of symptoms from a checklist, there are many different ways one could meet the criteria. There are 35 different ways one could pick 3 criteria from 7 (DSM-IV alcohol dependence) and 330 ways to pick 4 from 11 (DSM-5 severe AUD). The clinical heterogeneity likely reflects the genetic heterogeneity of the disease. The difficulties of genetic studies are compounded by environmental heterogeneity in access to alcohol and social norms related to drinking.

\section{Alcohol metabolism and the risk for AUD}

The genes with the clearest contribution to the risk for alcoholism and alcohol consumption are alcohol dehydrogenase $1 \mathrm{~B}(A D H 1 B)$ and aldehyde dehydrogenase 2 (ALDH2; mitochondrial aldehyde dehydrogenase), two genes central to the metabolism of alcohol (Figure 1) ${ }^{20}$. Alcohol is metabolized primarily in the liver, although there is some metabolism in the upper GI tract and stomach. The first step in ethanol metabolism is oxidation to acetaldehyde, catalyzed primarily by ADHs; there are 7 closely related ADHs clustered on chromosome 4 (reviewed $i^{20}$ ). The second step is metabolism of the acetaldehyde to acetate by ALDHs; again, there are many aldehyde dehydrogenases, among which ALDH2 has the largest impact on alcohol consumption ${ }^{20}$.

Acetaldehyde is a toxic intermediate, and systemic buildup of acetaldehyde results in unpleasant feelings such as dizziness, nausea, and tachycardia. Individuals carrying even a single copy of the $A L D H 2 * 504 K(A L D H 2 * 2$ allele; rs671) display the "Asian flushing reaction" when they consume even small amounts of alcohol; this includes prominent facial flushing, tachycardia, and nausea, and deters most individuals from excessive consumption of ethanol, although some can drink large quantities and become alcoholic despite this.

$A L D H 2 * 504 K$ is relatively common in East Asia, where up to 30-40\% of Han Chinese and Japanese carry at least one copy; however, it is extremely rare outside Asia. Nearly no individuals of European or African descent carry this allele ${ }^{21-23}$. The mechanism by which the $A L D H 2 * 504 K$ allele works is known. The replacement of a glutamate residue in position 504 of the ALDH2 enzyme with lysine severely inhibits the enzyme activity ${ }^{20,24,25}$. Most of the ALDH2 enzyme, which functions as a tetramer, is inactivated and degraded when a person carries even a single $A L D H 2 * 504 K$ allele $^{25}$. This leads to a major buildup of acetaldehyde in the circulation. It is similar to having disulfiram (Antabuse $®$ ) in one's system at all times. $A L D H 2 * 504 K$ has repeatedly been demonstrated to have a protective effect against AUDs ${ }^{20,21,26,27}$. But the protection against alcoholism afforded by a single copy of $A L D H 2 * 504 \mathrm{~K}$ is not complete, and is affected by societal circumstances. Higuchi ${ }^{28}$ demonstrated that the relative protection afforded by carrying a single copy of this allele declined dramatically in Japan between 1970 and 1992, a period that coincides with increasing social pressure for drinking as part of the business culture. The protection against alcoholism afforded by carrying two copies of the $A L D H 2 * 2$ allele is essentially complete, with those individuals typically unable to consume more than a very small amount of alcohol. The effects of the $A L D H 2 * 504 \mathrm{~K}$ allele are a dramatic demonstration both of the 
strong effect a genetic variant can have on risk for alcohol dependence, and also of how the effects of a protective allele can be overridden by environmental and social factors.

There are three known functional variants of the ADH1B enzyme ( $\beta-\mathrm{ADH})$, the cytosolic alcohol dehydrogenase at highest concentration in adult liver ${ }^{20,29}$. The reference allele, with a frequency of over $95 \%$ in populations of European descent, is generally known as $A D H 1 B$ $\left(A D H 1 B^{*} 1\right.$; known as $A D H 2^{*} 1$ in the older literature $\left.{ }^{\dagger}\right)$, and encodes an enzyme ( $\left.\beta 1-\mathrm{ADH}\right)$ with arginine at positions 48 and 370. ADH1B*48His (ADH1B*2; rs1229984) encodes $\beta 2-$ $\mathrm{ADH}$, with a histidine at position 48, and $A D H 1 B^{*} 370 C y s$ ( $A D H 1 B^{*} 3$; rs2066702) encodes $\beta 3-\mathrm{ADH}$ with cysteine at position 370 . The enzymes encoded by $A D H 1 B^{*} 48 \mathrm{His}$ and $A D H 1 B^{*} 370$ Cys metabolize ethanol in vitro at $30-40$-fold higher rates than does $\beta 1$ $\mathrm{ADH}^{20,29}$. A Japanese study of individuals checking into a hospital the day after heavy drinking showed that those with two copies of $A D H 1 B^{*} 1$ had higher blood alcohol concentrations than did those with at least one copy of $A D H 1 B^{*} 48 H i s$, indicating that there is a measurable effect in vivo ${ }^{30}$. Although some individuals with the $A D H 1 B^{*} 48 H i$ is allele report flushing upon consuming alcohol, it does not approach the dramatic Asian flushing reaction caused by the $A L D H 2 * 504 \mathrm{~K}$ allele, nor does it lead to the large increase in circulating acetaldehyde characteristic of $A L D H 2 * 504 K$ carriers. Nevertheless, the $A D H 1 B^{*} 48 H i$ is allele is nearly as protective as the heterozygous state of $A L D H 2 * 504 K$, with odds ratios for heterozygous carriers between 0.2 and $0.4^{20,21,31-33}$. It is thought that the faster metabolism of ethanol produces at least a transient increase in acetaldehyde in the liver which in turn triggers an aversive reaction. The protective $A D H 1 B^{*} 48 H i$ is allele is found at high frequency in East Asia, with over 90\% of Chinese and Japanese carrying at least one copy of the allele; it is at low frequency in Europe and Africa (generally under $5 \%$ ), and at modest frequency (about 20\%) in populations from the Middle East ${ }^{34-37}$. Because of its low allele frequency in Europeans, and its absence from arrays used in genome-wide association studies (GWAS), effects in people of European descent have, until recently, been hard to establish. A recent study demonstrated that $A D H 1 B^{*} 48 H i$ is has a similar effect on risk for alcoholism in Europeans as it does in Asians, with an odds ratio of $0.34\left(\mathrm{p}=6.6 \times 10^{-10}\right)^{32}$. ADHIB*370Cys is found almost only in populations of Eastern African descent, where as many as half of the individuals can carry the allele; it is rare in populations from Europe or Asia. $A D H 1 B^{*} 370 C y s$ also has a protective effect against alcohol dependence ${ }^{38}$, but those populations are under-studied.

$A L D H 2$ and $A D H 1 B$ show the largest effect on risk for alcoholism of any known genes. There are smaller effects of variants in other alcohol dehydrogenases, particularly ADHIC and $A D H 4^{\dagger}$, and reports of modest effects of other aldehyde dehydrogenase genes $^{20,33,38-40}$. However, studies have been complicated by the fact that many variants among the $A D H$ genes are in significant linkage disequilibrium (co-inherited). Another complication is that some of the functional variants with strongest effects on drinking (ADH1B*48His, ADH1B*370Cys and ALDH2*504K) are uncommon or rare in European populations, making many studies underpowered. Despite the strong effects of variations in these metabolism-related genes, they do not account for all of the genetic contribution to risk

$\dagger$ Note that the official names of several $\mathrm{ADH}$ genes have been changed, and the literature has been confused by some groups using non-standard names for some of the genes ${ }^{29}$. This review uses the official nomenclature. 
for alcoholism, particularly in populations (such as those from Europe) in which the allele frequencies for the variants with strongest effects are very low.

\section{Genes contributing to the risk of alcohol dependence}

There are several other genes that have been shown to contribute to the risk of alcohol dependence as well as key endophenotypes. The earliest genes were typically identified as a result of family-based analyses. In most cases, studies recruited families having multiple members with alcohol dependence; such families are likely to segregate variants that affect the risk of alcohol dependence. The most common initial approach was linkage analysis, in which markers throughout the genome were measured to identify chromosomal regions that appeared to segregate with disease across many families. Linkage studies are relatively robust to population differences in allele frequencies (because they test within-family inheritance), and can find a signal even if different variants in the same gene or region are responsible for the risk in different families. The drawback to this approach is that linkage studies find broad regions of the genome, often containing many hundreds of genes. In many cases, the initial linkage studies were followed by more detailed genetic analyses employing single nucleotide polymorphisms (SNPs) that were genotyped at high density across the linked regions. Some of the genes identified through this approach have been replicated across a number of studies and appear to be robust genetic findings. Others have not yet been replicated.

\section{GABRA2}

Linkage analysis of multiplex families recruited in the Collaborative Study on the Genetics of Alcoholism identified a region on chromosome $4 p$ that was linkage to alcohol dependence ${ }^{41}$; linkage in this region was supported by other studies ${ }^{42}$. SNP genotyping was performed in candidate genes within the linked region - notably in the $\mathrm{GABA}_{\mathrm{A}}$ receptor genes. A group of SNPs within the GABRA2 ( $\gamma$-amino butyric acid receptor A2) gene, which were in high linkage disequilibrium with each other (i.e. tightly correlated), were associated with alcohol dependence and appeared at least in part to underlie the observed linkage finding ${ }^{43}$. This association has been replicated in many different samples of European ${ }^{44-47}$ and African ancestry ${ }^{48}$. The finding was strongest in alcoholics with early onset or comorbid drug dependence ${ }^{45,49}$. There is evidence that the association may extend beyond GABRA2 and may also include the adjacent $G A B R G 1$ gene ${ }^{50,51}$. Analyses raise the possibility that there may be distinct effects in each gene $\mathrm{H}^{48,50}$ or there may be long range haplotypes that contribute to the risk of alcohol dependence ${ }^{52}$.

In parallel with analyses of alcohol dependence, the COGA investigators also examined the evidence of linkage with other alcohol-related phenotypes such as EEG- $\beta$. Alcoholics have increased power in the $\beta$ frequency of the electroencephalogram ${ }^{53,54}$, as do their offspring, who have not been exposed to alcohol ${ }^{55,56}$. Thus, EEG- $\beta$ is a heritable trait variable rather than simply a marker of excessive alcohol exposure. EEG- $\beta$ are high frequency oscillations important in short-range neural communication. Of note, the initial linkage peak on chromosome $4 \mathrm{p}$ was stronger with EEG- $\beta^{57,58}$. A set of SNPs in GABRA2, which overlapped with SNPs associated with alcohol dependence, was associated with this electrophysiological phenotype ${ }^{43}$. More recently, SNPs in GABRA2 have been associated 
with excess EEG fast activity in a sample of alcohol dependent and control individuals from the $\mathrm{UK}^{59}$. SNPs in GABRA2 are also associated with impulsiveness and variation in insula activity responses as measured in a fMRI monetary incentive delay task ${ }^{47}$.

\section{CHRM2}

The muscarinic cholinergic receptor 2 gene (CHRM2) was also associated with alcohol dependence in a linkage study followed up by genotyping candidate genes in the region. Other groups have replicated this finding ${ }^{60}$, and, like GABRA2, it appears to be strongest in the alcoholics with early onset or comorbid drug dependence ${ }^{61}$. Again, like GABRA2, an electrophysiological endophenotype focused studies on this gene ${ }^{62,63}$.

\section{Genome-wide Association Studies}

With the advent of microarrays that can measure hundreds of thousands to millions of single nucleotide polymorphisms (SNPs) across the genome, genome-wide association studies (GWAS) have provided a relatively unbiased way to identify specific genes that contribute to a phenotype. To date, GWAS have focused on common variants, with allele frequencies of 5\% or higher. Most GWAS are case-control studies or studies of quantitative traits in unrelated subjects, but family-based GWAS provide another approach. GWAS are beginning to yield robust findings, although the experience in many diseases is that very large numbers of subjects will be needed. To date, individual GWAS studies on alcohol dependence and related phenotypes have been relatively modest in size, and most do not reach genome-wide significance. This may reflect both the limited sample sizes and the clinical and genetic heterogeneity of the disease. As noted above, the functional $A D H 1 B$ polymorphism is not represented on GWAS platforms; GABA-receptor genes are often nominally significant but well below genome-wide significance in these studies. Thus, the genes and SNPs found through GWAS have had little overlap with previous findings based on candidate genes/pathways and linkage analyses.

Nearly all GWAS studies to date have been only modestly powered due to sample sizes that are in the hundreds or a few thousand. As a result, most have detected associations that do not meet stringent genome-wide thresholds. A few have attained genome-wide significance thresholds, but even among these, there has been little overlap in the genes found to be associated with alcohol dependence or alcohol related phenotypes. We highlight a few studies and results that have been reported that utilize key alcohol-related phenotypes and which illustrate several points. Rietschel and Treutlein have recently published a comprehensive review of GWAS studies on alcoholism ${ }^{64}$.

\section{PECR}

An initial genome-wide study of German male inpatients followed up by targeted genotyping of top SNPs and joint analysis provided evidence for association of alcohol dependence with two SNPs in the $3^{\prime}$ flanking region of PECR, peroxisomal trans-2-enoylcoA [coenzyme A] reductase ${ }^{65}$, a member of the short-chain dehydrogenase family of enzymes. PECR is located within broad linkage peaks for several alcohol-related traits, including alcoholism ${ }^{66}$, comorbid alcoholism and depression ${ }^{67}$, level of response to alcohol $^{68}$, and amplitude of the $\mathrm{P} 3(00)$ response $^{69,70}$. 


\section{KCNJ6}

A notable success in GWAS of alcohol-related endophenotypes focused on frontal theta band event related oscillations (theta ERO). Event-related oscillations (EROs) are highly heritable neuroelectric correlates of cognitive processes that exhibit deficits in alcoholics as well as their offspring at high risk to develop alcoholism, and thus are a good endophenotype. Analyses in 117 families densely affected by alcohol dependence revealed genome-wide significant association of theta ERO with several SNPs in KCNJ6 ( $p=4.7 \times$ $\left.10^{-10}\right)^{71}$. KCNJ6 encodes a potassium inward rectifier channel, GIRK2, whose activation contributes to slow inhibitory postsynaptic potentials that modulate neuronal excitability, and therefore influences neuronal networks ${ }^{72,73}$. KCNJ6 modulates opioid effects on analgesia and addiction in humans ${ }^{74}$; animal models have shown GIRK channels are directly activated by ethanol and are important effectors in both opioid- and ethanol-induced analgesia $^{74,75}$ and are considered a viable drug target.

\section{AUTS2}

A large meta-analysis of alcohol consumption (g/day/kg body weight) in 12 European population-based samples detected genome-wide significant evidence $\left(\mathrm{p}=4 \times 10^{-8}\right)$ of association with SNPs in the autism susceptibility candidate 2 gene $(A U T S 2)^{76}$. The association was supported by evidence that AUTS 2 expression in human brain tissue was related to genotype, and that mouse lines selected for alcohol preference differed in its expression. Furthermore, studies in Drosophila found that downregulation of an AUTS2 homolog resulted in reduced alcohol sensitivity ${ }^{76}$. Subsequent analyses suggest that the expression of AUTS2 may be downregulated in heroin dependent individuals as compared with controls ${ }^{77}$. Its molecular function is not known.

\section{IP011-HTR1A}

Some genes may contribute to an increased susceptibility to addictions in general. One study used a staged meta-analysis to explore comorbid alcohol and nicotine dependence and detected genome-wide evidence of association with SNPs spanning a region on chromosome 5 that includes both IPOII (importin 11) and HTRIA (5-hydroxytryptamine (serotonin) receptor $1 \mathrm{~A}, \mathrm{G}$ protein-coupled $)^{78}$. Importins are involved in transport of proteins and RNA between nucleus and cytoplasm, and serotonin has been implicated in many neural processes; HTR1A agonists reduce the anxiety-like behavior induced by repeated ethanol withdrawals in rats ${ }^{79}$. Analyses of RNA expression in lymphoblastoid cell lines suggested that SNPs within this region on chromosome 5 had cis-acting regulatory effects on the expression of HTRIA or IPOII.

In the study of complex disorders, it has become apparent that quite large sample sizes are critical if robust association results are to be identified which replicate across studies. Unfortunately, studies of alcohol dependence have not yet attained these sample sizes. Metaanalyses, which combine results across a number of studies in order to attain the critical sample sizes needed, are being developed. 


\section{Genetics of alcohol-associated diseases}

Alcohol affects a very large number of diseases. A recent meta-analysis found that alcohol consumption was causally related to a large number of diseases, ranging from infectious diseases such as tuberculosis and pneumonia, cardiovascular diseases, cirrhosis, and many cancers, particularly of the upper aerodigestive tract, colon, rectum and liver ${ }^{1}$. Genes that affect alcohol consumption, including those noted above that affect the very heavy consumption that is a key aspect of AUDs, can affect the risk for a disease caused in part by alcohol $^{29}$. They may increase the overall risk by increasing drinking, or reduce risk by reducing drinking. Some alleles that reduce heavy drinking can, nevertheless, increase risk for disease in the subset of individuals who drink heavily despite having them.

The GI tract is exposed to very high levels of alcohol as it passes through the mouth, esophagus, stomach and intestinal tract, and most ethanol passes through the liver before entering the circulation. Alcohol levels in common drinks range from approximately $5 \%$ (1.1 M) for beer, $11-15 \%$ for wine $(\sim 3 \mathrm{M})$ and $40 \%$ for spirits $(\sim 9 \mathrm{M})$. The oral cavity and esophagus are directly exposed to those levels, and the liver is exposed to high levels from the portal circulation. Thus it is not surprising that diseases of the GI system, including cirrhosis, pancreatitis, and cancers of the upper GI tract are affected by alcohol consumption ${ }^{80-86}$.

There is evidence that heavy episodic (binge) drinking, which results in exposure of tissues to high levels of alcohol, is particularly harmful ${ }^{81,87,88}$. Binge drinking is generally defined as a man consuming 5 standard drinks within 2 hours; women are typically smaller and have a lower percentage of body water, so 4 standard drinks can reach similar alcohol levels. A standard drink is defined in the US as 12 ounces of beer, 5 ounces of wine or 1.5 ounces of spirits, all of which approximate $14 \mathrm{~g}$ of pure ethanol). The strong effects of binge drinking suggest that merely calculating an average number of drinks per week is likely to obscure many effects of alcohol, since it treats 2 standard drinks per day (14 per week) the same as 7 drinks on each of two days per week.

Because of their obvious relationship to the disposition of alcohol in the body, studies have examined the relationship between genes encoding alcohol and aldehyde dehydrogenases and several GI diseases. Variants in $A D H$ and $A L D H$ genes that at least transiently increase acetaldehyde levels generally reduce heavy drinking and risk for alcoholism, as noted above. But among those who drink heavily despite this, the same genes may increase cancer risk by increasing levels of acetaldehyde in the tissues ${ }^{29}, 80,82-86$. Studies have been complicated by the difficulty in disentangling these effects, and by the fact that many variants among the $A D H$ genes are in significant linkage disequilibrium (at least partially co-inherited).

\section{Future directions}

It is now appreciated that a whole spectrum of allele frequencies and effect sizes may play roles, from common variations with small effects through rare variants of large effect. As whole exome and whole genome sequencing technologies come down in cost, they are being applied to identifying rare variants. For studies of rare variants, families are quite valuable for sorting out true positives from the background of individual variations that we all harbor. 


\section{Conclusions}

Family studies have consistently demonstrated that there is a substantial genetic contribution to alcohol dependence. Over the past two decades, several genes underlying susceptibility have been identified. Extensive study of the alcohol metabolizing genes has demonstrated their important role in disease risk. Additional genes have been identified that have expanded our understanding of the genes and pathways involved; however, the number of findings to date is modest. There are several likely reasons for this. First and perhaps foremost, most studies of alcohol-related phenotypes have been small - hundreds or a few thousand samples. Most robust associations that have been reported in common disease have employed tens of thousands of samples and are now beginning to combine several studies of these magnitude into even larger meta analyses. The alcohol research community has begun to form larger consortia for meta-analyses and it is anticipated that with the resulting increase in sample size the number of robust associations will increase. A second approach that will likely benefit the alcohol research community will be greater examination of pathways or gene sets. These approaches have been quite fruitful for some studies and need to be employed in analyses of alcohol-related traits and phenotypes. Over the next few years, we anticipate the identification of additional common and rare variants contributing to the risk of alcohol dependence.

\section{Acknowledgments}

Related work in the authors' laboratories is supported by grants from the National Institutes of Health, AA008401, AA006460, AA020892, AA007611.

\section{References}

1. Rehm J, et al. The relation between different dimensions of alcohol consumption and burden of disease: an overview. Addiction. 2010; 105:817-43. [PubMed: 20331573]

2. World_Health_Organization. Global status report on alcohol and health. 2011

3. Lim SS, et al. A comparative risk assessment of burden of disease and injury attributable to 67 risk factors and risk factor clusters in 21 regions, 1990-2010: a systematic analysis for the Global Burden of Disease Study 2010. Lancet. 2013; 380:2224-60. [PubMed: 23245609]

4. American_Psychiatric_Association. Diagnostic and Statistical Manual of Mental Disorders. 2000 Text Revision.

5. Hasin DS, Stinson FS, Ogburn E, Grant BF. Prevalence, correlates, disability, and comorbidity of DSM-IV alcohol abuse and dependence in the United States: results from the National Epidemiologic Survey on Alcohol and Related Conditions. Arch Gen Psychiatry. 2007; 64:830-42. [PubMed: 17606817]

6. Dawson DA, Goldstein RB, Grant BF. Differences in the Profiles of DSM-IV and DSM-5 Alcohol Use Disorders: Implications for Clinicians. Alcohol Clin Exp Res. 2013; 37(Suppl 1):E305-13. [PubMed: 22974144]

7. Agrawal A, Heath AC, Lynskey MT. DSM-IV to DSM-5: the impact of proposed revisions on diagnosis of alcohol use disorders. Addiction. 2011; 106:1935-43. [PubMed: 21631621]

8. American_Psychiatric_Association. Diagnostic and Statistical Manual of Mental Disorders: DSM-5. AMERICAN PSYCHIATRIC PUBLISHING; 2013.

9. Mewton L, Slade T, McBride O, Grove R, Teesson M. An evaluation of the proposed DSM-5 alcohol use disorder criteria using Australian national data. Addiction. 2011; 106:941-50. [PubMed: 21205055] 
10. Heath AC. Genetic influences on alcoholism risk: a review of adoption and twin studies. Alc Health Res World. 1995; 19:166-171.

11. Sigvardsson S, Bohman M, Cloninger CR. Replication of the Stockholm Adoption Study of alcoholism. Confirmatory cross-fostering analysis. Arch Gen Psychiatry. 1996; 53:681-7. [PubMed: 8694681]

12. Cloninger CR, Bohman M, Sigvardsson S. Inheritance of alcohol abuse: Cross-fostering analysis of adopted men. Arch Gen Psychiatry. 1981; 38:861-868. [PubMed: 7259422]

13. Bohman M, Sigvardsson S, Cloninger CR. Maternal inheritance of alcohol abuse. Cross-fostering analysis of adopted women. Arch Gen Psychiatry. 1981; 38:965-9. [PubMed: 7283667]

14. Heath AC, et al. Genetic and environmental contributions to alcohol dependence risk in a national twin sample: consistency of findings in women and men. Psychol Med. 1997; 27:1381-96. [PubMed: 9403910]

15. Prescott CA, Kendler KS. Genetic and environmental contributions to alcohol abuse and dependence in a population-based sample of male twins. Am J Psychiatry. 1999; 156:34-40. [PubMed: 9892295]

16. Kendler KS, Neale MC, Heath AC, Kessler RC, Eaves LJ. A twin-family study of alcoholism in women. Am J Psychiatry. 1994; 151:707-715. [PubMed: 8166312]

17. Pickens RW, et al. Heterogeneity in the inheritance of alcoholism: a study of male and female twins. Arch Gen Psychiatry. 1991; 48:19-28. [PubMed: 1984758]

18. McBride WJ, Li TK. Animal models of alcoholism: neurobiology of high alcohol-drinking behavior in rodents. Crit Rev Neurobiol. 1998; 12:339-69. [PubMed: 10348615]

19. Foroud T, Edenberg HJ, Crabbe JC. Genetic Research: Who Is At Risk for Alcoholism? Alcohol Research \& Health. 2010; 33:64-75. [PubMed: 23579937]

20. Hurley TD, Edenberg HJ. Genes encoding enzymes involved in ethanol metabolism. Alcohol Res. 2012; 34:339-44. [PubMed: 23134050]

21. Li D, Zhao H, Gelernter J. Strong protective effect of the aldehyde dehydrogenase gene (ALDH2) 504lys (*2) allele against alcoholism and alcohol-induced medical diseases in Asians. Hum Genet. 2011

22. Oota $\mathrm{H}$, et al. The evolution and population genetics of the ALDH2 locus: random genetic drift, selection, and low levels of recombination. Ann Hum Genet. 2004; 68:93-109. [PubMed: 15008789]

23. Luczak SE, Glatt SJ, Wall TJ. Meta-analyses of ALDH2 and ADH1B with alcohol dependence in Asians. Psychol Bull. 2006; 132:607-21. [PubMed: 16822169]

24. Larson HN, Weiner H, Hurley TD. Disruption of the coenzyme binding site and dimer interface revealed in the crystal structure of mitochondrial aldehyde dehydrogenase "Asian" variant. J Biol Chem. 2005; 280:30550-6. [PubMed: 15983043]

25. Crabb DW, Edenberg HJ, Bosron WF, Li TK. Genotypes for aldehyde dehydrogenase deficiency and alcohol sensitivity. The inactive ALDH2(2) allele is dominant. J Clin Invest. 1989; 83:314-6. [PubMed: 2562960]

26. Thomasson HR, et al. Alcohol and aldehyde dehydrogenase genotypes and alcoholism in Chinese men. American journal of human genetics. 1991; 48:677-81. [PubMed: 2014795]

27. Eng MY, Luczak SE, Wall TL. ALDH2, ADH1B, and ADH1C genotypes in Asians: a literature review. Alcohol Res Health. 2007; 30:22-7. [PubMed: 17718397]

28. Higuchi S. Polymorphisms of ethanol metabolizing enzyme genes and alcoholism. Alcohol Alcohol Suppl. 1994; 2:29-34. [PubMed: 8974313]

29. Edenberg, HJ.; Bosron, WF. Comprehensive Toxicology. McQueen, CA., editor. Oxford: Academic Press; 2010. p. 111-130.

30. Yokoyama A, et al. Contribution of the alcohol dehydrogenase-1B genotype and oral microorganisms to high salivary acetaldehyde concentrations in Japanese alcoholic men. Int $\mathbf{J}$ Cancer. 2007; 121:1047-54. [PubMed: 17471563]

31. Chen $\mathrm{CC}$, et al. Interaction between the functional polymorphisms of the alcohol-metabolism genes in protection against alcoholism. Am J Hum Genet. 1999; 65:795-807. [PubMed: 10441588] 
32. Bierut LJ, et al. ADH1B is associated with alcohol dependence and alcohol consumption in populations of European and African ancestry. Mol Psychiatry. 2012; 17:445-50. [PubMed: 21968928]

33. Whitfield JB. Alcohol dehydrogenase and alcohol dependence: variation in genotype-associated risk between populations. Am J Hum Genet. 2002; 71:1247-50. author reply 1250-1. [PubMed: 12452180]

34. Thomasson HR, et al. Alcohol and aldehyde dehydrogenase genotypes and alcoholism in Chinese men. Am J Hum Genet. 1991; 48:677-81. [PubMed: 2014795]

35. Osier MV, et al. ALFRED: An allele frequency database for anthropology. Am J Phys Anthropol. 2002; 119:77-83. [PubMed: 12209575]

36. $\mathrm{Li} \mathrm{H}$, et al. Geographically separate increases in the frequency of the derived ADH1B*47His allele in eastern and western Asia. Am J Hum Genet. 2007; 81:842-6. [PubMed: 17847010]

37. Osier MV, et al. A global perspective on genetic variation at the ADH genes reveals unusual patterns of linkage disequilibrium and diversity. Am J Hum Genet. 2002; 71:84-99. [PubMed: 12050823]

38. Edenberg HJ, et al. Association of alcohol dehydrogenase genes with alcohol dependence: a comprehensive analysis. Hum Mol Genet. 2006; 15:1539-49. [PubMed: 16571603]

39. Kuo PH, et al. Association of ADH and ALDH genes with alcohol dependence in the Irish Affected Sib Pair Study of alcohol dependence (IASPSAD) sample. Alcoholism, clinical and experimental research. 2008; 32:785-95.

40. Luo X, et al. Multiple ADH genes modulate risk for drug dependence in both African- and European-Americans. Hum Mol Genet. 2007; 16:380-90. [PubMed: 17185388]

41. Reich T, et al. Genome-wide search for genes affecting the risk for alcohol dependence. Am J Med Genet. 1998; 81:207-15. [PubMed: 9603606]

42. Long JC, et al. Evidence for genetic linkage to alcohol dependence on chromosomes 4 and 11 from and autosome-wide scan in an American Indian population. Am J Med Genet (Neuropsych Genet). 1998; 81:216-221.

43. Edenberg HJ, et al. Variations in GABRA2, encoding the alpha 2 subunit of the GABA(A) receptor, are associated with alcohol dependence and with brain oscillations. Am J Hum Genet. 2004; 74:705-14. [PubMed: 15024690]

44. Covault J, Gelernter J, Hesselbrock V, Nellissery M, Kranzler HR. Allelic and haplotypic association of GABRA2 with alcohol dependence. Am J Med Genet B Neuropsychiatr Genet. 2004; 129:104-9. [PubMed: 15274050]

45. Fehr C, et al. Confirmation of association of the GABRA2 gene with alcohol dependence by subtype-specific analysis. Psychiatr Genet. 2006; 16:9-17. [PubMed: 16395124]

46. Lappalainen J, et al. Association between alcoholism and gamma-amino butyric acid alpha2 receptor subtype in a Russian population. Alcohol Clin Exp Res. 2005; 29:493-8. [PubMed: 15834213]

47. Villafuerte $S$, et al. Impulsiveness and insula activation during reward anticipation are associated with genetic variants in GABRA2 in a family sample enriched for alcoholism. Mol Psychiatry. 2012; 17:511-9. [PubMed: 21483437]

48. Ittiwut $\mathrm{C}$, et al. GABRG1 and GABRA2 Variation Associated with Alcohol Dependence in African Americans. Alcohol Clin Exp Res. 2011

49. Agrawal A, et al. Association of GABRA2 with drug dependence in the collaborative study of the genetics of alcoholism sample. Behav Genet. 2006; 36:640-50. [PubMed: 16622805]

50. Covault J, Gelernter J, Jensen K, Anton R, Kranzler HR. Markers in the 5'-region of GABRG1 associate to alcohol dependence and are in linkage disequilibrium with markers in the adjacent GABRA2 gene. Neuropsychopharmacology. 2008; 33:837-48. [PubMed: 17507911]

51. Enoch MA, et al. GABRG1 and GABRA2 as Independent Predictors for Alcoholism in Two Populations. Neuropsychopharmacology. 2008

52. Enoch MA, et al. GABRG1 and GABRA2 as independent predictors for alcoholism in two populations. Neuropsychopharmacology. 2009; 34:1245-54. [PubMed: 18818659] 
53. Costa L, Bauer L. Quantitative electroencephalographic differences associated with alcohol, cocaine, heroin and dual-substance dependence. Drug Alcohol Depend. 1997; 46:87-93. [PubMed: 9246556]

54. Rangaswamy M, et al. Beta power in the EEG of alcoholics. Biol Psychiatry. 2002; 52:831-42. [PubMed: 12372655]

55. Rangaswamy M, et al. Resting EEG in offspring of male alcoholics: beta frequencies. Int $\mathrm{J}$ Psychophysiol. 2004; 51:239-51. [PubMed: 14962576]

56. Bauer LO, Hesselbrock V. EEG autonomic, and subjective correlates of the risk for alcoholism. J Stud Alcohol. 1993; 54:577-589. [PubMed: 8412148]

57. Porjesz B, et al. Linkage disequilibrium between the beta frequency of the human EEG and a GABAA receptor gene locus. Proc Natl Acad Sci U S A. 2002; 99:3729-3733. [PubMed: 11891318]

58. Ghosh S, et al. Linkage mapping of beta 2 EEG waves via non-parametric regression. Am J Med Genet. 2003; 118B:66-71. [PubMed: 12627469]

59. Lydall GJ, et al. Genetic association study of GABRA2 single nucleotide polymorphisms and electroencephalography in alcohol dependence. Neurosci Lett. 2011; 500:162-6. [PubMed: 21683760]

60. Luo X, et al. CHRM2 gene predisposes to alcohol dependence, drug dependence and affective disorders: results from an extended case-control structured association study. Hum Mol Genet. 2005; 14:2421-34. [PubMed: 16000316]

61. Dick DM, et al. Alcohol dependence with comorbid drug dependence: genetic and phenotypic associations suggest a more severe form of the disorder with stronger genetic contribution to risk. Addiction. 2007; 102:1131-9. [PubMed: 17567401]

62. Jones KA, et al. A cholinergic receptor gene (CHRM2) affects event-related oscillations. Behav Genet. 2006; 36:627-39. [PubMed: 16823639]

63. Jones KA, et al. Linkage and linkage disequilibrium of evoked EEG oscillations with CHRM2 receptor gene polymorphisms: implications for human brain dynamics and cognition. Int $\mathbf{J}$ Psychophysiol. 2004; 53:75-90. [PubMed: 15210286]

64. Rietschel M, Treutlein J. The genetics of alcohol dependence. Ann N Y Acad Sci. 2012

65 . Treutlein J, et al. Genome-wide association study of alcohol dependence. Arch Gen Psychiatry. 2009; 66:773-84. [PubMed: 19581569]

66. Hill SY, et al. A genome wide search for alcoholism susceptibility genes. Am J Med Genet B Neuropsychiatr Genet. 2004; 128B:102-13. [PubMed: 15211641]

67. Nurnberger JI Jr, et al. Evidence for a locus on chromosome 1 that influences vulnerability to alcoholism and affective disorder. Am J Psychiatry. 2001; 158:718-24. [PubMed: 11329392]

68. Schuckit MA, et al. A genome-wide search for genes that relate to a low level of response to alcohol. Alcohol Clin Exp Res. 2001; 25:323-9. [PubMed: 11290841]

69. Begleiter H, et al. Quantitative trait loci analysis of human event-related brain potentials: P3 voltage. Electroencephalogr Clin Neurophysiol. 1998; 108:244-250. [PubMed: 9607513]

70. Porjesz B, et al. Linkage and linkage disequilibrium mapping of ERP and EEG phenotypes. Biol Psychol. 2002; 61:229-48. [PubMed: 12385677]

71. Kang SJ, et al. Family-based genome-wide association study of frontal theta oscillations identifies potassium channel gene KCNJ6. Genes Brain Behav. 2012; 11:712-9. [PubMed: 22554406]

72. Luscher C, Jan LY, Stoffel M, Malenka RC, Nicoll RA. G protein-coupled inwardly rectifying K+ channels (GIRKs) mediate postsynaptic but not presynaptic transmitter actions in hippocampal neurons. Neuron. 1997; 19:687-95. [PubMed: 9331358]

73. Blednov YA, Stoffel M, Chang SR, Harris RA. Potassium channels as targets for ethanol: studies of G-protein-coupled inwardly rectifying potassium channel 2 (GIRK2) null mutant mice. J Pharmacol Exp Ther. 2001; 298:521-30. [PubMed: 11454913]

74. Lotsch J, Pruss H, Veh RW, Doehring A. A KCNJ6 (Kir3.2, GIRK2) gene polymorphism modulates opioid effects on analgesia and addiction but not on pupil size. Pharmacogenet Genomics. 2010; 20:291-7. [PubMed: 20220551] 
75. Ikeda K, et al. Molecular mechanisms of analgesia induced by opioids and ethanol: is the GIRK channel one of the keys? Neurosci Res. 2002; 44:121-131. [PubMed: 12354627]

76. Schumann G, et al. Genome-wide association and genetic functional studies identify autism susceptibility candidate 2 gene (AUTS2) in the regulation of alcohol consumption. Proceedings of the National Academy of Sciences of the United States of America. 2011; 108:7119-24. [PubMed: 21471458]

77. Chen YH, Liao DL, Lai CH, Chen CH. Genetic analysis of AUTS2 as a susceptibility gene of heroin dependence. Drug and Alcohol Dependence.

78. Zuo L, et al. Genome-Wide Significant Association Signals in IPO11-HTR1A Region Specific for Alcohol and Nicotine Codependence. Alcohol Clin Exp Res.

79. Overstreet DH, Knapp DJ, Moy SS, Breese GR. A 5-HT1A agonist and a 5-HT2c antagonist reduce social interaction deficit induced by multiple ethanol withdrawals in rats. Psychopharmacology (Berl). 2003; 167:344-52. [PubMed: 12677355]

80. Lewis SJ, Smith GD. Alcohol, ALDH2, and esophageal cancer: a meta-analysis which illustrates the potentials and limitations of a Mendelian randomization approach. Cancer Epidemiol Biomarkers Prev. 2005; 14:1967-71. [PubMed: 16103445]

81. Gupta S, Wang F, Holly EA, Bracci PM. Risk of pancreatic cancer by alcohol dose, duration, and pattern of consumption, including binge drinking: a population-based study. Cancer Causes Control. 2010; 21:1047-59. [PubMed: 20349126]

82. Yokoyama A, et al. Esophageal squamous cell carcinoma and aldehyde dehydrogenase-2 genotypes in Japanese females. Alcohol Clin Exp Res. 2006; 30:491-500. [PubMed: 16499490]

83. Yokoyama A, et al. Genetic polymorphisms of alcohol and aldehyde dehydrogenases and glutathione S-transferase M1 and drinking, smoking, and diet in Japanese men with esophageal squamous cell carcinoma. Carcinogenesis. 2002; 23:1851-9. [PubMed: 12419833]

84. Seitz HK, Meier P. The role of acetaldehyde in upper digestive tract cancer in alcoholics. Translational research : the journal of laboratory and clinical medicine. 2007; 149:293-7. [PubMed: 17543846]

85. Seitz HK, Homann N. The role of acetaldehyde in alcohol-associated cancer of the gastrointestinal tract. Novartis Found Symp. 2007; 285:110-9. discussion 119-4, 198-9. [PubMed: 17590990]

86. Seitz HK, Becker P. Alcohol metabolism and cancer risk. Alcohol Res Health. 2007; 30:38-41. 44-7. [PubMed: 17718399]

87. Ruidavets JB, et al. Patterns of alcohol consumption and ischaemic heart disease in culturally divergent countries: the Prospective Epidemiological Study of Myocardial Infarction (PRIME). BMJ. 2010; 341:c6077. [PubMed: 21098615]

88. Graff-Iversen $\mathrm{S}$, et al. Divergent associations of drinking frequency and binge consumption of alcohol with mortality within the same cohort. J Epidemiol Community Health. 2012 


\section{Bullet points}

- Alcohol dependence is a common, complex genetic disease, with many variants in many genes contributing to the risk.

- Genes related to alcohol metabolism are known to have strong effects on risk; there are functional variants of $A D H 1 B$ and $A L D H 2$ that are protective against alcoholism, with odds ratios in the range of 0.2 to 0.4 .

- Several other genes, including GABRA2 and CHRM2, have been associated with alcohol dependence in many studies. There is evidence for a role of many other genes in affecting the disease and traits associated with it.

- As larger samples are assembled for meta-analyses and a wider range of alleles tested, the roles of many additional genes are likely to be uncovered.

- Excessive alcohol consumption, particularly binge drinking, contributes to many other diseases, including cirrhosis and cancers of the upper aerodigestive tract, colon, rectum and liver. Genes that affect the quantity and frequency of drinking impact the risk of many of these diseases. 


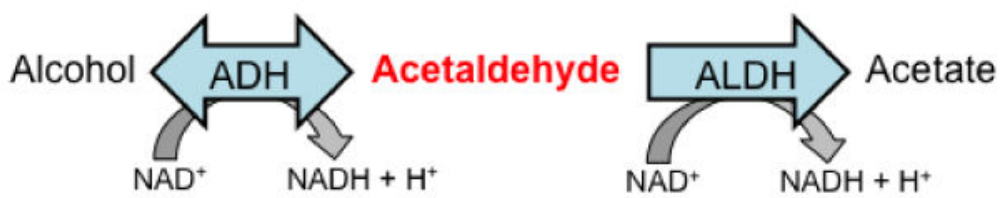

Figure 1.

Major pathway of alcohol metabolism. 


\section{Table 1}

\section{Criteria for alcohol use disorders}

\begin{tabular}{|l|l|l|l|}
\hline \multirow{2}{*}{ Criteria } & \multicolumn{2}{|c|}{ DSM-IV } & $\begin{array}{l}\text { DSM-5: alcohol use } \\
\text { disorder (two or more or } \\
\text { the criteria) }\end{array}$ \\
\cline { 2 - 4 } & $\begin{array}{l}\text { Alcohol abuse } \\
\text { (one of more of } \\
\text { the criteria) }\end{array}$ & $\begin{array}{l}\text { Alcohol dependence } \\
\text { (three or more of the } \\
\text { criteria during 1 year) }\end{array}$ & NA \\
\hline Failure to meet major role obligations & Included & RAtained \\
\hline Recurrent hazardous use & Included & NA & Retained \\
\hline Recurrent alcohol-related legal problems & Included & NA & Omitted \\
\hline Continued use despite recurrent social problems & Included & NA & Retained \\
\hline Tolerance & NA & Included & Retained \\
\hline $\begin{array}{l}\text { Alcohol withdrawal (or drinking and/or taking drugs to } \\
\text { avoid withdrawal) }\end{array}$ & NA & Included & Retained \\
\hline Drinking more than intended & NA & Included & Retained \\
\hline Unsuccessful attempts to cut down on use & NA & Included & Retained \\
\hline Excessive time related to alcohol (obtaining, hangover) & NA & Included & Retained \\
\hline Impaired social or work activities due to alcohol & NA & Included & Retained \\
\hline Use despite known physical or psychological consequences & NA & Included & Retained \\
\hline Alcohol craving & NA & Omitted & Included \\
\hline
\end{tabular}

* DSM-IV is hierarchical: if an individual meets criteria for alcohol dependence that diagnosis is given; abuse is only diagnosed if the individual does not meet criteria for dependence. Abbreviation: NA, not applicable. DSM-5 is subdivided into moderate ( 2 or 3 criteria) and severe (4 or more criteria) AUD. 